\title{
INVASIVE STATUS OF Tarebia granifera BASED ON DENSITY OF POPULATION IN RIVER OF GUNUNG SEJUK VILLAGE, SOUTH BUTON REGENCY
}

\author{
LM. Junaidin Sirza ${ }^{1}$ - Muhammad Fajar Purnama ${ }^{2}$ - Khoirul \\ Anwar $^{3} \cdot$ Salwiyah $^{2} \cdot$ Abdullah $^{2}$
}

\begin{abstract}
This research was conducted from May to August 2020, located in the Wandoke Watershed, Gunung Sejuk Village, South Buton Regency. This study aims to analyze the invasive status of the alien species Tarebia granifera based on the perspective of its population density in the river of Gunung Sejuk village. This research is intended to examine the dominance of $T$. granifera species to local gastropod commodities in the typical habitats and niches of the Wandoke river. Determination of the station or location of the observation begins with a preliminary survey, making it easier to select and determine research stations. Determination of research stations using purposive sampling technique or method of designating stations deliberately, based on the presence of invasive alien species populations of $T$. granifera and T. grani-

\footnotetext{
1) Program Studi Pengelolaan Sumberdaya Perairan, Fakultas Pertanian, Universitas Muhammadiyah $\mathrm{Bu}-$ ton, Jl. Betoambari, Kota Bau-Bau, Sulawesi Tenggara $93724^{2}$ ) Jurusan Manajemen Sumberdaya Perairan, Fakultas Perikanan dan Ilmu Kelautan, Universitas Halu Oleo, Jl. H.E.A. Mokodompit, Kota Kendari, Sulawesi Tenggara $93232^{3}$ ) Asca Amoghasida Enginering Consultant, Jl. Bayem V No.8, Sendangguwo, Kec. Tembalang, Kota Semarang, Jawa Tengah 50273 Indonesia

E-mail: muhammadfajarpurnama@gmail.com
}

fera sampling using simple random sampling or T. granifera sampling is done randomly in a square transect measuring $100 \mathrm{~m}^{2}$, using a quadratic transect measuring $1 \mathrm{~m}^{2}$, with the assumption that each point in the transect measuring $100 \mathrm{~m}^{2}$ has homogeneous conditions. The population density of T. granifera at each station in the months of May - August (Spatial and Temporal) shows the size is not much different, where the density range is $21 \mathrm{ind} / \mathrm{m}^{2}$ $43.33 \mathrm{ind} / \mathrm{m}^{2}$. The results of measurement and population density analysis of T. granifera in the waters of the Wandoke river, Gunung Sejuk village is the massive empirical evidence of the invasive pattern of the thiaridae snail.

Keywords invasive, status, population, density, management, Tarebia granifera

\section{PENDAHULUAN}

Kabupaten Buton Selatan merupakan salah satu wilayah di Pulau Buton dengan potensi perikanan darat yang besar. Sebagai wilayah eksisting berbagai karakteristik perairan darat alami dan buatan (sungai, danau, rawa, ben- 
dungan, situ, embung dan drainase/tanggul) menjadikan ekosistem perairan tawar Kabupaten Buton Selatan sumber plasma nutfah komoditi ekonomis penting khas perikanan darat, salah satunya adalah komoditi gastropoda. Gastropoda atau kelompok siput banyak dimanfaatkan oleh masyarakat pribumi sebagai sumber pangan. Saat ini keberdaan komoditi gastropoda lokal perlahan mulai terdegradasi oleh kehadiran spesies asing invasif $T$. granifera di Perairan Darat Kabupaten Buton Selatan khususnya di daerah aliran sungai (DAS) Wandoke Desa Gunung Sejuk.

Merujuk penelitian sebelumnya oleh Purnama et al. (2019) bahwa spesies asing invasif $T$. granifera telah menginvasi seluruh wilayah daratan provinsi Sulawesi Tenggara (Kota Kendari, Kabupaten Konawe, Kabupaten Selatan, Kabupaten Utara, Kabupaten Bombana, Kabupaten Kolaka Timur, Kabupaten Kolaka dan Kabupaten Kolaka Utara), hal tersebut terlihat dari kehadiran dan dominasi $T$. granifera pada seluruh tipikal habitat dan relung di perairan darat (alami dan buatan), seperti sungai berarus deras dan berarus tenang, sungai berbatu dan bersubstrat pasir/kerikil, kali (sungai kecil), air terjun, persawaan, DAM, bendungan dan tanggul/drainase.

Kehadiran siput invasif tersebut dipastikan selalu mendominasi system relung dan habitat di perairan tawar Sulawesi Tenggara Klaster Daratan. Dasar empirik inilah yang menjadi landasan mengapa penelitian ini dilakukan, mengingat informasi ilmiah atau data penelitian mengenai spesies asing invasif $T$. granifera belum pernah dilakukan di Pulau Buton khususnya di Desa Gunung Sejuk Kabupaten Buton Selatan. Oleh karena itu untuk mengetahui status invasif $T$. granifera berdasarkan perspektif kepadatan populasinya, maka penelitian ini menjadi sangat penting untuk dilakukan, sebagai langkah awal dan sumber informasi vital dalam upaya pengendalian dan pengelolaan spesies asing invasif di perairan darat Sulawesi Tenggara, khususnya pulau Buton.

\section{MATERI DAN METODE}

Penelitian ini dilaksanakan selama 4 bulan yaitu Mei sampai dengan Agustus 2020, bertempat di DAS (Daerah Aliran Sungai) Wandoke Desa Gunung Sejuk, Kecamatan Sampolawa, Kabupaten Buton Selatan, Provinsi Sulawesi Tenggara. Penentuan stasiun atau lokasi pengamatan diawali oleh kegiatan survey pendahuluan, sehingga memudahkan dalam pemilihan dan penetapan lokasi pengambilan sampel. Penentuan stasiun penelitian menggunakan teknik purposive sampling atau metode penunjukkan stasiun secara sengaja, berdasarkan keberadaan populasi spesies asing invasif (SAI) $T$. granifera dan pengambilan sampel $T$. granifera menggunakan metode simple random sampling atau pengambilan sampel $T$. granifera dilakukan secara acak di dalam transek kuadrat berukuran 100 $\mathrm{m}^{2}$, menggunakan transek kuadrat ukuran $1 \mathrm{~m}^{2}$, dengan asumsi bahwa setiap titik di dalam transek ukuran $100 \mathrm{~m}^{2}$ memiliki kondisi yang homogen. Kegiatan eksplorasi dan pengambilan sampel spesies asing invasif pada setiap stasiun, dilakukan secara manual tanpa menggunakan alat tangkap khusus, dengan alat bantu sarung tangan. Hal ini didasarkan oleh kebiasaan hidup alami T. granifera di alam, yaitu mayoritas menempel pada bebatuan dan substrat keras lainnya, serta juga ditemukan di 


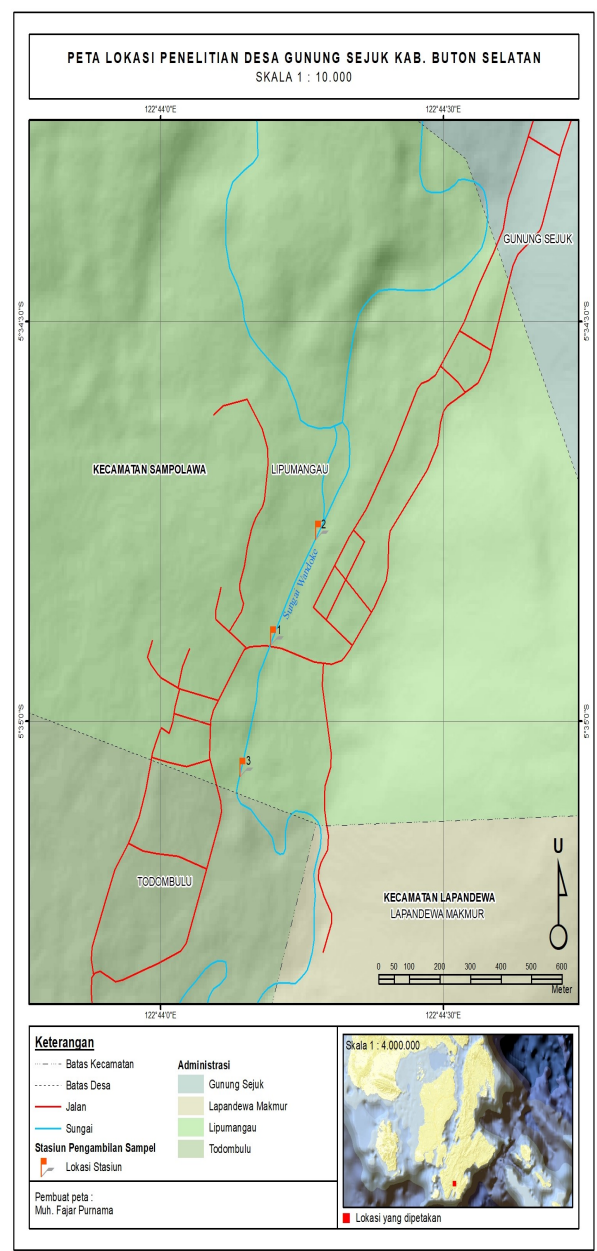

Figure 1 Peta Lokasi Penelitian (Desa Gn. Sejuk Kabupaten Buton Selatan)

permukaan substrat (epifauna), sehingga sangat memudahkan dalam proses pengambilannya. Pola invasif gastropoda T. granifera di sungai Wandoke Desa Gn. Sejuk, dianalisis berdasarkan perspektif kepadatan populasinya, menggunakan formulasi menurut Odum (1993). Berikut adalah peta detail lokasi dan stasiun pengambilan sampel T. granifera di Desa Gn. Sejuk Kabupaten Buton Selatan.

\section{HASIL DAN PEMBAHASAN}

Hasil analisis rata-rata kepadatan populasi spesies asing invasif $T$. granifera
Table 1 Rerata kepadatan $T$. granifera di setiap stasiun selama periode penelitian

\begin{tabular}{ccccc}
\hline \multirow{2}{*}{ Stasiun Penelitian } & \multicolumn{4}{c}{ Kepadatan Populasi $\left(\mathrm{Ind} / \mathrm{m}^{2}\right)$} \\
\cline { 2 - 5 } & Mei & Juni & Juli & Agustus \\
\hline Stasiun 1 & 21.33 & 24.33 & 30.33 & 31.66 \\
Stasiun 2 & 22 & 26.33 & 29 & 43.33 \\
Stasiun 3 & 21 & 24.66 & 29 & 33.33 \\
\hline
\end{tabular}

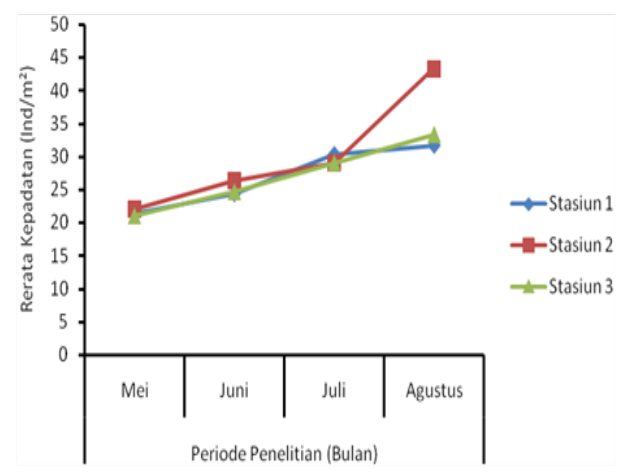

Figure 2 Rerata Kepadatan Populasi T. granifera

di DAS Wandoke pada masing-masing stasiun selama periode penelitian, menunjukan besaran yang tidak jauh berbeda, dimana kisarannya yaitu $21 \mathrm{Ind} / \mathrm{m}^{2}$ 43,33 Ind $/ \mathrm{m}^{2}$. Selain itu, hasil analisis juga memperlihatkan jumlah kepadatan berdasarkan stasiun dan periode penelitian relatif berbeda, dimana secara temporal kepadatan tertinggi diperoleh pada bulan Agustus (31,66 - 43,33 $\left.\mathrm{Ind} / \mathrm{m}^{2}\right)$ dan Juli $\left(29-30,33 \mathrm{Ind} / \mathrm{m}^{2}\right)$ dan terendah berturut-turut pada bulan Mei (21-24,33 Ind/ $\left./ \mathrm{m}^{2}\right)$ dan Juni (21,33 - 24,66 Ind/ $/ \mathrm{m}^{2}$ ), sedangkan secara spasial kepadatan tertinggi terdapat di stasiun $2\left(43,33 \mathrm{Ind} / \mathrm{m}^{2}\right)$ pada periode Agustus dan terendah terdapat di stasiun 3 - $\left(21 \mathrm{Ind} / \mathrm{m}^{2}\right)$ pada periode Mei. Tabulasi rerata kepadatan populasi $T$. granifera di DAS Wandoke Desa Gunung Sejuk Kabupaten Buton Selatan (spasial dan temporal) disajikan pada Tabel 1 .

Fluktuasi detail kepadatan populasi $\left(\mathrm{Ind} / \mathrm{m}^{2}\right)$ pada setiap stasiun selama periode penelitian disajikan dalam bentuk grafik pada Gambar 2. 


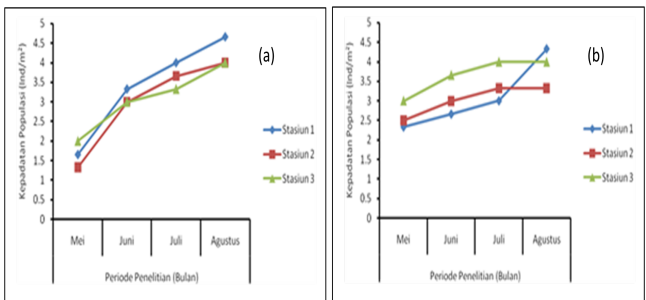

Figure 3 Kepadatan Populasi Spesies Asli, (a) Thiara scabra dan (b) Neritina pulligera

Grafik kepadatan populasi spesies asing invasif $T$. granifera di atas memperlihatkan pola peningkatan setiap bulannya di masing-masing stasiun. Hal ini terlihat dari kenaikan nilai rerata kepadatan setiap periode penelitian. Contoh pada Stasiun 1, berturut-turut selama periode penelitian (Mei-Agustus) yaitu $21.33 \mathrm{Ind} / \mathrm{m}^{2}, 24.33 \mathrm{Ind} / \mathrm{m}^{2}, 30.33 \mathrm{Ind} / \mathrm{m}^{2}$ dan $31.66 \mathrm{Ind} / \mathrm{m}^{2}$ ). Tren yang samapun terjadi pada stasiun 2 dan stasiun 3 selama periode penelitian.

Hasil analisis kepadatan populasi spesies asli di setiap stasiun selama periode penelitian, memperlihatkan besaran kepadatan yang sangat rendah $\left(1.33 \mathrm{Ind} / \mathrm{m}^{2}\right.$ - 4,66 Ind/ $\mathrm{m}^{2}$ ), meskiput tren nilai kepadatan pada setiap periode penelitian mengalami peningkatan. Kenaikan besaran nilai kepadatan populasi spesies asli ( $T$. scabra dan $N$. pulligera) juga terlihat rendah. Berikut adalah grafik kepadatan populasi spesies asli (T. scabra dan $N$. pulligera) di perairan sungai Wandoke, Desa Gunung Sejuk Kabupaten Buton selatan.

Grafik di atas menunjukan tren yang sama antara kedua spesies asli tersebut, dimana besaran nilai kepadatan populasinya selalu mengalami peningkatan setiap bulan (Periode penelitian), walaupun fluktuasinya tidak signifikan atau nilai rerata kepadatan T. scabra dan N. pulligera pada masing-masing stasiun, selama periode penelitian berada dalam kisaran yang sangat rendah $\left(1,33 \mathrm{Ind} / \mathrm{m}^{2}\right.$ - 4,66 Ind $/ \mathrm{m}^{2}$ ).

Status invasif spesies asing $T$. granifera di perairan sungai Wandoke Desa Gunung Sejek Kabupaten Buton Selatan, terbilang tinggi (massive) berdasarkan perspektif kepadatan populasi dan komparasinya terhadap kepadatan populasi spesies asli (indigenous species) di setiap periode penelitian pada masing-masing stasiun. Perbandingan minimal antara T. granifera dan spesies asli (T. scabra dan N. pulligera) pada ruang relung berukuran $1 \mathrm{~m}^{2}$ adalah $1: 21$ (Individu), hal ini menunjukan bahwa dominasi spesies asing invasif tersebut sangat tinggi terhadap spesies asli. Kondisi demikian hanya terjadi pada spot sampling yang bersentuhan langsung dengan pinggir atau dinding sungai, sedangkan pada areal tengah sampai mendekati dinding sungai hanya ditemukan spesies asing invasif $T$. granifera dengan kisaran kepadatan yang tinggi yaitu $21-43 \mathrm{Ind} / \mathrm{m}^{2}$.

Selain itu terlihat bahwa pada bulan agustus merupakan puncak kepadatan tertinggi populasi $T$. granifera maupun spesies asli, hal ini pada dasarnya disebabkan oleh faktor makanan. Pada periode Agustus, substrat dasar perairan berbatu sungai Wandoke, ditutupi oleh komunitas makroalga dalam hal ini lumut dan merupakan sumber makanan dari spesies asing invasif $T$. granifera dan spesies asli, dikarenakan kebiasaan makan T. granifera, T. scabra dan $N$. pulligera adalah herbivora atau pemakan tumbuhan (Purnama et al., 2020; Purnama et al., 2019; Rustiasih et al., 2018).

Pernyataan di atas sejalan dengan hasil penelitian mutakhir Purnama et al (2020) bahwa $T$. granifera merupakan spesies asing invasif (SAI) yang tersebar di seluruh perairan darat alami dan buatan Provinsi 
Sulawesi Tenggara Klaster Daratan (Kabupaten Kolaka Utara, Kabupaten Kolaka, Kabupaten Kolaka Timur, Kabupaten Bombana, Kabupaten Konawe, Kabupaten Konawe Utara, Kabupaten Konawe Selatan dan Kota Kendari). Kehadiran populasi $T$. granifera selalu mendominasi habitat dan relung tempat gastropoda thiaridae tersebut hidup, selain itu kemampuan adaptasi terhadap parameter lingkungan (fisik-kimia) dan berbagai bentuk karakteristik morfologi perairan darat (Sungai, Danau, Rawa, Situ Bendungan, DAM, Tanggul/Drainase dan Embung), membuat $T$. granifera mampu menempati seluruh tipe ekosistem tersebut. Kemudian, selain resistensi yang tinggi terhadap perubahan kualitas perairan, T. granifera juga memiliki tipe reproduksi dengan mekanisme kerja cepat, tanpa memerlukan kehadiran pejantan dalam proses pembuatan sel telur, sistem reproduksi tersebut adalah parthenogenesis atau sistem reproduksi tanpa kopulasi atau kawin, sehingga memungkinkan bagi $T$. granifera mempercepat proses rekruitmen populasinnya di alam dan secara langsung menyebabkan ledakan populasi $T$. granifera yang tidak terkendali.

Beberapa penelitian terdahulu juga menerangkan hal yang sama, yaitu siput Thiaridae jenis $T$. granifera merupakan spesies asing invasif, yang keberdaannya dapat mengganggu kesetimbangan ekosistem, terlebih lagi apabila kawasan tersebut menyediakan kondisi lingkungan yang sesuai dengan preferensi habitat atau relungnya. Selain itu, kemampuan reproduksi dengan sistem partenogenesis membuat siput $T$. granifera dengan cepat dapat melakukan reproduksi tanpa melakukan kopulasi terlebih dahulu dengan lawan jenis, dikarenakan sis- tem reproduksi ini, menjadikan betina dapat memproduksi sel telur yang berkembang tanpa melalui proses fertilisasi (Rustiasih et al., 2018; Didham et al., 2007; Charles and Dukes, 2008; Moslemi et al., 2012 dan Rangel et al., 2011). Aktivitas dominasi oleh spesies asing invasif T. granifera secara alami di alam merupakan ancaman besar bagi keberlanjutan dan kelesteraian spesies asli/lokal (Native species) di perairan sungai Wandoke Desa Gunung Sejuk Kabupaten Buton Selatan. Meyerson and Mooney (2007) : Didham et al. (2007) menyatakan bahwa degradasi lingkungan pada dasarnya disebabkan oleh konversi lahan dan umum konversi lahan merupakan penyebab utama terjadinya perubahan lingkungan yang secara spesifik memicu penyebaran spesies asing invasif. Alaydrus (2013) mengidentifikasi bahwa kemerosotan keanekaragaman hayati disebabkan oleh berbagai hal, antara lain karena konservasi lahan, eksploitasi yang berlebihan, dan introduksi spesies asing (invasive alien species; IAS).

Salah satu komponen utama perubahan lingkungan adalah introduksi spesies asing invasif, dimana penyebaran spesies asing invasif pada dasarnya menjadi salah satu ancaman signifikan terhadap keanekaragaman hayati fauna akuatik lokal (endemik). Wittenberg and Cock (2001) menyatakan bahwa Spesies asing invasif selain mengancam keanekaragaman hayati juga membebankan biaya yang sangat besar pada bidang perikanan. Secara lebih spesifik menyatakan bahwa spesies asing yang invasive diduga menjadi penyebab langsung dari hilangnya biodiversitas di dunia. Introduksi spesies asing dapat berpengaruh terhadap keseimbangan sistem ekologi dan secara langsung dapat berakibat pada 
hilangnya spesies endemik lokal, sehingga eksistensi alien spesies dikhawatirkan dapat mengancam biodiversitas hayati akuatik dunia khususnya Indonesia, terlebih lagi Indonesia berada pada posisi yang penting dalam peta keanekaragaman hayati di dunia karena termasuk dalam sepuluh Negara dengan keanekaragaman hayati yang tinggi (Alaydrus, 2013).

\section{SIMPULAN}

Status invasif $T$. granifera di perairan sungai Wandoke, Desa Gunung Sejuk Kabupaten Buton Selatan "sangat tinggi (massive)" berdasarkan data kepadatan populasi-nya (21-43,33 $\left.\mathrm{Ind} / \mathrm{m}^{2}\right)$, ruang relung di sepanjang permukaan substrat seluruh bagian sungai, hanya ditemukan spesies asing invasif tersebut, spesies asli (indigenous species) khas sungai wandoke seperti jenis Thiara scabra dan Neritina pulligera serta beberapa siput bangsa Melanoides, hanya menempati bebatuan pinggiran atau dinding sungai, dengan kepadatan populasi yang sangat rendah $\left(1,33-4,66 \mathrm{Ind} / \mathrm{m}^{2}\right)$ dan juga terdapat spesies asing invasif $T$. granifera diantara beberapa spesies asli tersebut.

Acknowledgements : Penulis mengucapkan terimkasih yang sebesar-besarnya kepada rekan tim sampling lapangan (Sdr. Aksa Julianto AM, Muh. Arjuna Sakti dan Nurfajar) atas perkenaannya membantu dan memfasilitasi pada saat penelitian di Pulau Buton khususnya Pengamatan sampel di DAS Wandoke Desa Gunung Sejuk Kabupaten Buton Selatan.

\section{References}

Alaydrus, R. (2013). Spesies tumbuhan asing invasif (invasive alien plant species) dan peluang pengawasannya dalam penyelenggaraan perkarantinaan tumbuhan.

Charles, H. and Dukes, J. S. (2008). Impacts of invasive species on ecosystem services. In Biological invasions, pages 217-237. Springer.
Didham, R. K., Tylianakis, J. M., Gemmell, N. J., Rand, T. A., and Ewers, R. M. (2007). Interactive effects of habitat modification and species invasion on native species decline. Trends in ecology \& evolution, 22(9):489-496.

Meyerson, L. A. and Mooney, H. A. (2007). Invasive alien species in an era of globalization. Frontiers in Ecology and the Environment, 5(4):199-208.

Moslemi, J. M., Snider, S. B., MacNeill, K., Gilliam, J. F., and Flecker, A. S. (2012). Impacts of an invasive snail (tarebia granifera) on nutrient cycling in tropical streams: the role of riparian deforestation in trinidad, west indies. PLoS One, 7(6):e38806.

Odum, E. P. (1993). Dasar-dasar ekologi edisi ketiga. Gadjah Mada Univesity Press, Yogyakarta.

Purnama, M., Sari, S., Admaja, A., et al. (2020). Spatial distribution of invasive alien species tarebia granifera in southeast sulawesi, indonesia. $A A C L$ Bioflux, 13(3):1355-1365.

Purnama, M. F., Admaja, A. K., and Haslianti, H. (2019). Bivalvia dan gastropoda perairan tawar di sulawesi tenggara. Jurnal Penelitian Perikanan Indonesia, 25(3):191-202.

Rangel, R., Anguilar, Gamboa Anguilar, J., Garcia Morales, M., and Ortiz Lezama Oscar, M. (2011). Tarebia granifera (lamarck, 1822) en la region hidrologica grijalva usumacinta en tabasco, mexico. Acta zoologica mexicana, 27(1):103-114.

Rustiasih, E., Arthana, I. W., and Sari, A. H. W. (2018). Keanekaragaman dan kelimpahan makroinvertebrata sebagai biomonitoring kualitas perairan tukad badung, bali. Current Trends in Aquatic Science, 1(1):16-23.

Wittenberg, R. and Cock, M. J. (2001). Invasive alien species: a toolkit of best prevention and management practices. CABI.

Kontribusi: Sirza, L.M.J: Mengambil data Lapangan; Purnama, M.F:Mengambil Data Lapangan, Analisis Data dan Menulis Hasil Penelitian dan Pembahasan; Anwar, K: Membuat Peta Penelitian; Salwiyah dan Abdullah: Mengambil Data Lapangan \& Editing. 